\title{
Effect of nanoparticles in volatile production during seed storage of groundnut
}

\author{
K. KRISHNA SHYLA* AND N. NATARAJAN \\ Department of Seed Science and Technology, Tamil Nadu Agricultural University, COIMBATORE (T.N.) INDIA \\ (Email : shylaja.agri@gmail.com)
}

\begin{abstract}
In the present study, seeds were evaluated for their influence at laboratory condition with dry dressing seed treatment, using inorganic and organic nanopowder that can maintain the seed quality in groundnut VRI 2. Fresh seeds of groundnut were treated with inorganic NPs of ZnO, Ag and $\mathrm{TiO}_{2}$ each @ 750, 1000 and $1250 \mathrm{mg} \mathrm{kg}^{-1}$ and organic nanopowder of CLP and FSP each @ 1,2 and $3 \mathrm{~g} \mathrm{~kg}^{-1}$ and stored for 12 months under ambient condition and to assess their effects on physiological parameter of seeds and explore of volatile metabolites emitted from the aged seeds relate with seed quality. Seeds treated with inorganic NPs and organic nanopowders did not vary for seed germination analyzed immediately after treatment. However, after 12 months of storage, seeds treated with ZnO NPs @ $1000 \mathrm{mg} \mathrm{kg}^{-1}$ enhanced germination (77\%) against the control (66\%). In the case of organic nanopowders, seed treated with FSP@ 2g and CLP@ $3 \mathrm{~g} \mathrm{~kg}^{-1}$ had higher germination (75 and 75\%) compared to control (66\%). Volatiles emitted from the seeds treated with NPs revealed that the number of compound emitted under aldehyde, ketone, acids, ether, ester and carboxyl groups was less (20) while the control had 36 compouds, expressing a negative correlation to the germination. The present investigation clearly demonstrated the effect of inorganic NPs of ZnO @ $1000 \mathrm{mg} \mathrm{kg}^{-1}$ and Ag @ 1250 $\mathrm{mg} \mathrm{kg}-1$ and the organic nanopowders of FSP @ $2 \mathrm{~g} \mathrm{~kg}^{-1}$ of seeds in maintaining the quality.
\end{abstract}

Key Words : Nanopowders, Groundnut, Seed quality, Volatile production

View Point Article : Shyla, K. Krishna and Natarajan, N. (2016). Effect of nanoparticles in volatile production during seed storage of groundnut. Internat. J. agric. Sci., 12 (2) : 191-198, DOI:10.15740/HAS/IJAS/12.2/191-198.

Article History : Received : 01.02.2016; Revised : 09.02.2016; Accepted : 12.04.2016

\footnotetext{
* Author for correspondence
} 